\begin{tabular}{c}
\hline $\begin{array}{c}\text { Brazilian Journal } \\
\text { of Chemical } \\
\text { Engineering }\end{array}$ \\
\hline
\end{tabular}

ISSN 0104-6632

Printed in Brazil

www.abeq.org.br/bjche

Vol. 25, No. 04, pp. 759 - 764, October - December, 2008

\title{
Ca ALGINATE AS SCAFFOLD FOR IRON OXIDE NANOPARTICLES SYNTHESIS
}

\author{
P. V. Finotelli ${ }^{1}$, D. A. Sampaio ${ }^{2}$, M. A. Morales ${ }^{1}$, A. M. Rossi ${ }^{3}$ and M. H. Rocha-Leão ${ }^{2 *}$ \\ ${ }^{1}$ Instituto de Química, Universidade Federal do Rio de Janeiro, Centro de Tecnologia, B1. E, \\ CEP: 21949-900, Rio de Janeiro - RJ, Brazil. \\ E-mail:mhrl@eq.ufrj.br \\ ${ }^{2}$ Escola de Química, Universidade do Estado do Rio de Janeiro, \\ CEP: 21949-900, Rio de Janeiro - RJ, Brazil. \\ ${ }^{3}$ Centro Brasileiro de Pesquisas Físicas, Rio de Janeiro - RJ, Brazil.
}

(Received: January 25, 2006 ; Accepted: June 11, 2008)

\begin{abstract}
Recently, nanotechnology has developed to a stage that makes it possible to process magnetic nanoparticles for the site-specific delivery of drugs. To this end, it has been proposed as biomaterial for drug delivery system in which the drug release rates would be activated by a magnetic external stimuli. Alginate has been used extensively in the food, pharmaceutical and biomedical industries for their gel forming properties in the presence of multivalent cations. In this study, we produced iron oxide nanoparticles by coprecipitation of $\mathrm{Fe}(\mathrm{III})$ and $\mathrm{Fe}(\mathrm{II})$. The nanoparticles were entrapped in $\mathrm{Ca}$ alginate beads before and after alginate gelation. XRD analysis showed that particles should be associated to magnetite or maghemite with crystal size of 9.5 and $4.3 \mathrm{~nm}$, respectively. Studies using Mössbauer spectroscopy corroborate the superparamagnetic behavior. The combination of magnetic properties and the biocompatibility of alginate suggest that this biomaterial may be used as biomimetic system.

Keywords: Alginate; Nanotechnology and Magnetite.
\end{abstract}

\section{INTRODUCTION}

The synthesis of biocompatible superparamagnetic materials has long been of interest in biomedical applications including magnetic resonance imaging for clinical diagnosis, magnetic drug targeting, hyperthermia anti-cancer strategy, and enzyme immobilization (Kim et al., 2001; Reynolds et al., 2000; Lubbe et al., 1996; Bergemann et al., 1999; Chan et al., 1993; Jordan et al., 1999; Dyal et al., 2003). Entrapment techniques using liposomes, alginate and some other biopolymers are usually applied for different clinical procedures such as drugs release, hyperthermia or for local contrast enhancement in MR imaging. In this last example magnetic nanoparticles are used.
Polymer containing iron-oxide particles provides a better particles flow into the tissue fluids. When these particles are superparamagnetic, they can easily be magnetized by an external magnetic field and immediately dispersed once the magnet is removed (Saiyed et al., 2003). The efficacy in many medical applications depends on the particle nature and size distribution besides the polymer/nanoparticles morphology and surface chemistry (Weissleder et al., 1990; Thode et al., 1997).

$\mathrm{Fe}_{3} \mathrm{O}_{4}$ (magnetite) is a technologically important magnetic material that has a wide range of applications in magnetic storage devices (Dionne, 1975; Matsumoto et al, 1991; Morisako et al., 1987). Magnetite $\left(\mathrm{Fe}_{3} \mathrm{O}_{4}\right)$ is biocompatible and therefore is

*To whom correspondence should be addressed 
one of the most extensively used biomaterials for different applications ranging from cell separation and drug delivery to hyperthermia. Other than this, a large number of magnetic materials in bulk as well as in the form of nanoparticles have been exploited for a variety of medical applications. According to Cheng et al, 2005; the in vitro cytotoxicity test revealed that the magnetite particles exhibited excellent biocompatibility. $\mathrm{Fe}_{3} \mathrm{O}_{4}$ nanoparticles are commonly produced via co-precipitation of $\mathrm{Fe}$ (II) and Fe(III) ions by a base, usually sodium hydroxide or aqueous ammonia (Kang et al., 1996; Hong et al., 1997; Fried et al., 2001) or they may be made by thermal decomposition of alkaline solution of Fe(III) chelate in the presence of hydrazine and by sonochemical decomposition of hydrolyzed Fe(II) salt followed by thermal treatment (Sapieszko et al., 1980; Vijayakumar et al., 2000).

Polysaccharides such as alginates have been used extensively in the food, cosmetics, pharmaceutical and biomedical industries for their gel forming properties in the presence of multivalent cations. Alginates are composed of (1-4)-linked $\beta$-Dmannuronic acid ( $\mathrm{M}$ units) and $\alpha$-L-guluronic acid (G units) monomers which vary in amount and sequential distribution along the polymer chain depending on the source of the alginate (Martinsen et al., 1989). Divalent cations like $\mathrm{Ca}^{2+}$ cooperatively bind between the G-blocks of adjacent alginate chains, producing the so-called "egg-box" structure, creating ionic interchain bridges which cause gelling of aqueous alginate solutions. Thus, the development of a system based in alginate microcapsules nucleated by iron oxide nanoparticles may be a potential drug delivery device controlled by an external oscillating magnetic field, contributing to human health care (Häfeli, 2004). Such delivery system offers numerous advantages compared to conventional dosage forms, which include improved efficacy, reduced toxicity, and improved patient compliance and convenience.

In the current study, iron oxide nanoparticles were produced by coprecipitation of $\mathrm{Fe}$ (II) and $\mathrm{Fe}$ (III) in ammonium hydroxide medium. The nanoparticles were entrapped in $\mathrm{Ca}$ alginate beads before and after alginate gelation to investigate the influence of this polymer during the process of particle growth. The particles were investigated by X-ray diffraction (XRD) and Mössbauer spectroscopy to analyze the nature and sizes of the iron oxide particles.

\section{MATERIALS AND METHODS}

Sodium alginate was obtained from Keltone LV. Sodium alginate solutions $(2 \%, \mathrm{w} / \mathrm{v})$ had viscosity at $25^{\circ} \mathrm{C}$ and $60 \mathrm{rpm}$ (No. 2 spindle) of 100-300 mPa.s, as determined with LV model of the Brookfield viscosimeter. The ratio of mannuronic acid to guluronic acid residues $(\mathrm{M} / \mathrm{G})$ was between 0.4 and 1.9. The ferric chloride $\left(\mathrm{FeCl}_{3} \cdot 6 \mathrm{H}_{2} \mathrm{O}\right)$ was obtained from Nuclear Inc. The solution of ferrous chloride $\left(\mathrm{FeCl}_{2}\right)$ was prepared by a reaction between $\mathrm{FeSO}_{4} \cdot 7 \mathrm{H}_{2} \mathrm{O}$ (Química Moderna) and $\mathrm{CaCl}_{2} \cdot 2 \mathrm{H}_{2} \mathrm{O}$ (Isofar) in a stoichiometric ratio. The methanol and ammonium hydroxide were obtained from Synth and Merck, respectively.

Iron oxide nanoparticles were prepared from $\mathrm{Fe}(\mathrm{III})$ and $\mathrm{Fe}$ (II) solutions at a constant temperature. The nanoparticles were entrapped in $\mathrm{Ca}$ alginate beads before (sample B) and after (sample A) alginate gelation. Calcium alginate beads were prepared at $300 \mathrm{~K}$ by dropping sodium alginate solution into a calcium chloride solution. After gelation the beads were allowed to further polymerize then washed several times and dried in the oven at 24 hours. The diameter of the alginates spheres was about 400 micrometers.

$\mathrm{X}$-ray diffraction (XRD) measurements were made in a SEIFERT-FPM GmbH equipped with $\mathrm{Cu}$ $\mathrm{K} \alpha$ radiation source. Mössbauer spectroscopy (MS) measurements were performed in the transmission mode using a $25 \mathrm{mCi}{ }^{57} \mathrm{Co}: R h$ source moving in a sinusoidal mode. The center shift (CS) reported is relative to iron at room temperature (RT).

\section{RESULTS AND DISCUSSION}

Powder XRD was carried out to identify the nanocrystalline structure of the iron oxide species. The X-ray diffraction (XRD) pattern of alginate beads whose iron oxide nanoparticles were produced in presence of calcium alginate (sample A) is shown in Fig. 1. The XRD powder diffraction pattern shows the formation of a crystalline mineral phase of maghemite or magnetite, which crystallize in the inverse espinel structure (space group $\mathrm{Fd} \overline{3} \mathrm{~m}$ ). Because these structures have similar XRD patterns, it is difficult to exclude the formation of maghemite instead of magnetite in the samples. Magnetite is obtained according to the reaction:

$$
2 \mathrm{FeCl}_{3}+\mathrm{FeCl}_{2}+8 \mathrm{NH}_{4} \mathrm{OH} \rightarrow \mathrm{Fe}_{3} \mathrm{O}_{4}+8 \mathrm{NH}_{4} \mathrm{Cl}+4 \mathrm{H}_{2} \mathrm{O}
$$


However, maghemite $\left(\gamma-\mathrm{Fe}_{2} \mathrm{O}_{3}\right)$ is commonly formed by oxidation of magnetite. The magnetic properties of maghemite are very close to magnetite. Thus, it is very difficult to distinguish between magnetite and magnetite/maghemite phases because $\mathrm{X}$-ray diffraction patterns are not evident in that respect. Fig. 2 displays the X-ray diffraction (XRD) pattern of alginate beads whose iron oxide nanoparticles were produced without presence of calcium alginate (sample B) and it presented the same results described above as the sample A.

The broadening of the XRD lines of the superparamagnetic magnetites is caused by diffraction of X-rays over crystal volumes whose dimensions are comparable to the wavelength of the $\mathrm{X}$-ray. This effect can be used to calculate the dimensions of the crystal with the Scherrer formula

$\mathrm{t}=\mathrm{K} \lambda / \beta \cos \theta$

$\beta=\left(B^{2}-b^{2}\right)^{1 / 2}$

where $\mathrm{t}=$ crystal thickness $(\mathrm{nm}) ; \mathrm{K}=$ Scherrer factor; $\lambda=X$-ray wavelength (nm); $\beta=$ excess line broadening (radians); $\theta=$ Bragg angle (radians); $\mathrm{B}=$ linewidth; and $\mathrm{b}=$ instrument line broadening (determined with a suitable standard). For linewidths measured as the full width at half maximum peak intensity, $\mathrm{K}=0.89$ (Cullity, 1978).

From XRD, the crystallite size has been estimated as 4.3 and $9.5 \mathrm{~nm}$ for sample $\mathrm{A}$ and sample $\mathrm{B}$, respectively. Cheng et al, 2005 synthesized $\mathrm{Fe}_{3} \mathrm{O}_{4}$ nanoparticles using Fe(II) and Fe(III) salt chemical coprecipitation with tetramethylammonium hydroxide
$\left(\mathrm{N}\left(\mathrm{CH}_{3}\right)_{4} \mathrm{OH}\right)$ in an aqueous solution which resulted in an iron oxide particles with $9 \mathrm{~nm}$ diameter in size. Their result is according to ours, when iron oxide nanoparticles were synthesized before alginate gelation. The decrease of particle size of about $50 \%$ may be explained by the presence of the calcium alginate polymer, which acts as an "egg-box" like scaffold for iron oxide particles growth.

The Mössbauer spectrum at 300K, Fig. 3 (a), for iron oxide before alginate gelation (sample B) shows a hyperfine sextet and doublet peaks (near the center of the spectrum) indicative of magnetic and a paramagnetic iron, respectively. The fitted parameters of the MS spectrum are isomer shift (IS) of $0.36(7) \mathrm{mm} / \mathrm{s}$, quadrupole splitting (QS) of $0.72(1) \mathrm{mm} / \mathrm{s}$. Possible explanation of the magnetic splitting at room temperature is formation of largesized $\mathrm{Fe}_{3} \mathrm{O}_{4}$ particles with magnetic moment blocked at room temperature.

In Fig. 3 (b), the Mössbauer spectrum at $300 \mathrm{~K}$ for iron oxide nanoparticles produced after alginate gelation (sample A) shows a doublet as indicative of superparamagnetic particles of magnetite or maghemite, with no evidence of magnetic order (absence of magnetic sextet pattern). The fitted parameters of the spectrum are isomer shift (IS) of $0.34(2) \mathrm{mm} / \mathrm{s}$, quadrupole splitting (QS) of $0.72(2)$ $\mathrm{mm} / \mathrm{s}$. These MS parameters are similar to those of sample B indicating that the iron oxide particles have the same nature for both samples. The absence of hyperfine spectrum in sample A suggests that smaller particles are produced when iron oxides nanoparticles were synthesized in presence of calcium alginate.

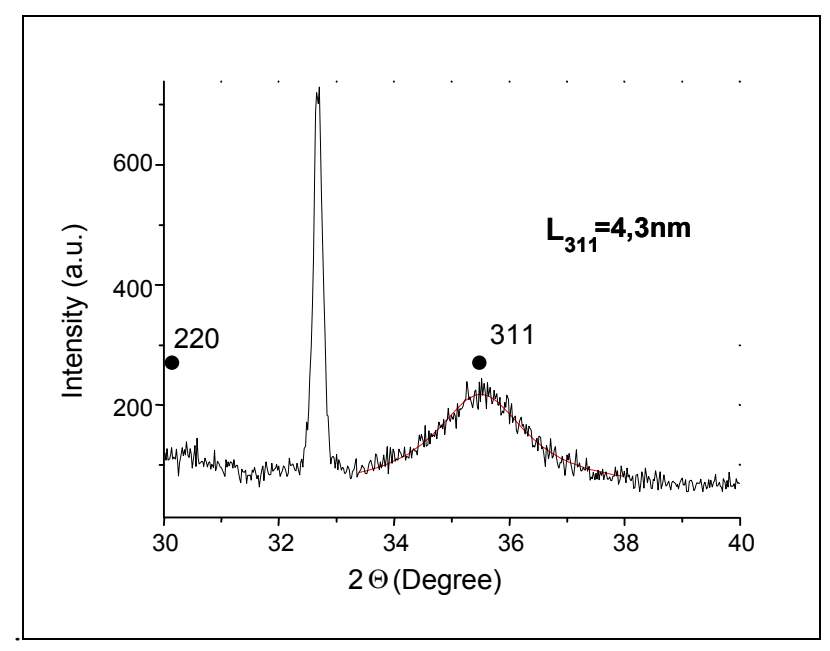

Figure 1: X-ray powder diffraction of the alginate beads containing $\mathrm{Fe}_{3} \mathrm{O}_{4}$ nanoparticles produced after alginate gelation (sample A). 


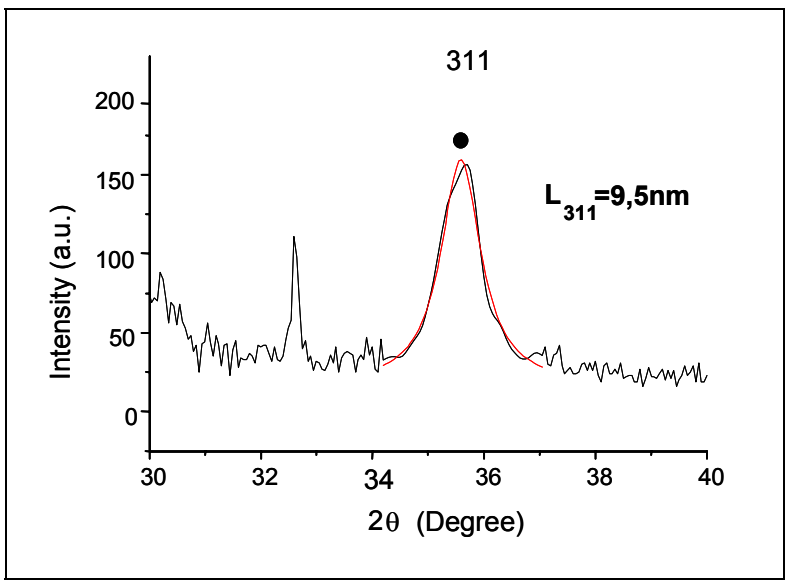

Figure 2: $\mathrm{X}$-ray powder diffraction of the alginate beads containing $\mathrm{Fe}_{3} \mathrm{O}_{4}$ nanoparticles produced before alginate gelation (sample B).
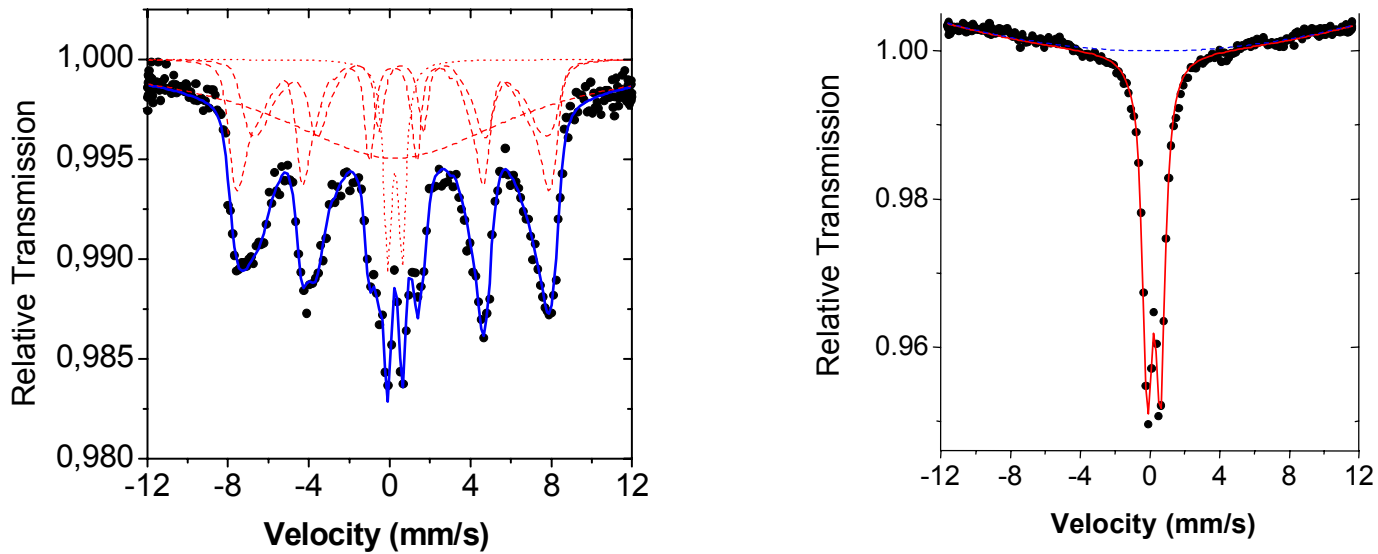

Figure 3: Mössbauer spectra. (a) iron oxide nanoparticles produced before alginate gelation (sample B);

(b) iron oxide nanoparticles produced after alginate gelation (sample A).

\section{CONCLUSION}

The results strongly suggest that the use of a polymer in the material synthesis limits particle size. The iron oxide produced before alginate gelation generate particles that are significantly bigger than the iron oxide produced after alginate gelation in which polymer (calcium alginate) is present during the synthesis. Although the methods used to determinate the crystalline structure indicate that particles can be magnetite, it is not enough to precise exactly, because magnetite is easily oxidized to maghemite whose XRD and MS parameters are closer. In addition, to improve the characterization of the iron oxide particles is important to associate other techniques.
The applications of nano materials to biotechnology/biosciences (so-called nanobiotechnology), are gradually increasing, and is a challenging area for future research in health care. The use of magnetic materials in bio-fields is wide open. The combination of magnetic properties of iron nanoparticles with the biocompatibility of calcium alginate suggest that these materials have potential to be used as drug delivery system.

\section{ACKNOWLEDGMENTS}

This study was supported by the Brazilian Council for Scientific and Technological 
Development ( $\mathrm{CNPq} /$ Pronex $)$. The first author is grateful to CAPES for the financial support. The alginate was kindly supplied by ISP Alginates Inc.

\section{REFERENCES}

Bahadur, D., Giri, J. Biomaterials and magnetism Sadhana Vol.28, Parts 3 \& 4, June/August, p. 639-656 (2003).

Bergemann, C., Muller-Schulte, D., Oster, J., Brassard, L., Lubbe, A. S. Magnetic ion-exchange nano-and macroparticles for medical, biochemical and molecular biological applications.J Magn Magn Mater; 194, p. 45-52 (1999).

Chan, D. C. F., Kirpotin, D. B., Bunn, P. Synthesis andevaluation of colloidal magnetic iron oxides for the site-specific radiofrequency induced hyperthermia of cancer. J Magn Magn Mater; 122, p. 374-8 (1993).

Cheng, F. Y., Su, C. H., Yang, Y. S., Yeh, C. S., Tsai, C. Y., Wu., C. L., Wu, M. T., Shieh, D. B. Characterization of aqueous dispersions of $\mathrm{Fe}_{3} \mathrm{O}_{4}$ nanoparticles and their biomedical applications Biomaterials 26, p. 729-738 (2005).

Cullity, B. D. Elements of X-Ray Diffraction $-2^{\circ}$ ed., Addison-Wesley Publishing Company, Inc. (1978).

Dionne, G. F., A review of ferrites for microwave applications. Proc. IEEE 63, p. 77 (1975).

Dyal, A., Loos, K., Noto, M., Chang, S. W., Pagnoli, C, Sha, K. V. P. M., Ulman, A., Cowman, M., Gross, R. A. Activity of cândida rugosalipase immobilizedon $\mathrm{Fe}_{2} \mathrm{O}_{3}$ magnetic nanoparticles. J Am Chem Soc; 125, p. 1684-5 (2003).

Fried, T., Shemer, G., Markovich, G. Ordered TwoDimensional Arrays of Ferrite Nanoparticles. Adv. Mater. 13, p. 1158 (2001).

Hafeli, U. O. Magnetically modulated therapeutic systems. International Journal of Pharmaceutics, 277, p. 19-24 (2004).

Hong, C. Y., Jang, IJ., Horng, H. E., Hsu, CJ., Yao, Y. D., Yang, H., C. Ordered structures in $\mathrm{Fe}_{3} \mathrm{O}_{4}$ kerosene-based ferrofluids. J. Appl. Phys. 81, p. 4275 (1997).

Jordan, A., Scholz, R., Wust, P., Schirra, H., Schiestel, T., Schmidt, H., Felix, R. Endocytosis of dextran and silan-coated magnetite nanoparticles and the effect of intracellular hyperthermia on human mammary carcinoma cells in vitro. J Magn Magn Mater; 194, p. 185-96 (1999).
Kang, Y. S., Risbud, S., Rabolt, J. F., Stroeve, P. Synthesis and Characterization of NanometerSize $\mathrm{Fe}_{3} \mathrm{O}_{4}$ and $y-\mathrm{Fe}_{2} \mathrm{O}_{3}$ Particles. Chem. Mater. 8, p. 2209 (1996).

Kim, D. K., Zhang, Y., Kehr, J., Klason, T., Bjelke, B., Muhammed, M. Characterization and MRI stud $\mathrm{y}$ of surfactant-coated superparamagnetic nanoparticles administered into the rat brain. J Magn Magn Mater; 225, p. 256-61 (2001).

Lubbe, A. S., Bergemann, C., Riess, H. Clinical experiences with magnetic drug targeting: a phase I study with 40 -epidoxorubicin in 14 patients with advanced solid tumors. Cancer Res; 56, p. 4686 - 93 (1996).

Martinsen, A., Skjak-Brñk, G., Smidsrd, O. Alginate as immobilzation material. I. Correlation between chemical and physical properties of alginate gel beads. Biotechnol Bioeng; 33, p. 79-89 (1989).

Matsumoto, M., Morisako, A., Haeiwa, T. Pulsed laser deposition of strontium ferrite thin films. IEEE Trans. Magn. 6, p. 648 (1991).

Morisako, A., Matsumoto, M., Naoe, M. Sputtered $\mathrm{Mn}-\mathrm{Al}-\mathrm{Cu}$ films for magnetic recording media. IEEE Trans. Magn. 23, p. 56 (1987).

Pardoe, P., Chua-anusorn, W., St Pierre, T. G., Dobson, J. Structural and magnetic properties of nanoscale iron oxide particles synthesized in the presence of dextran or polyvinyl alcohol. J. Magn. Magn. Mater. 225, p. 41-46 (2001).

Reynolds, C. H., Annan, N., Beshah, K., Huber, J. H., Shaber, S. H., Lenkinski, R. E., Wortman, J. A. Gadolinium-loaded nanoparticles: new contrast agents for magnetic resonance imaging. $\mathrm{J}$ Am Chem Soc; 122, p. 8940-5 (2000).

Sapieszko, R. S., Matijevic, E. Preparation of welldefined colloidal particles by thermal decomposition of metal chelates J. Colloid Interface. Sci. 74, p. 405 (1980).

Saiyed, Z. M., Telang, S. D., Ramchand, C. N. Application of magnetic techniques in the field of drug discovery and biomedicine. BioMagnetic Research and Technology 1, p. 2 (2003).

Thode, K., Luck, M., Schroder, W., Semmler, W., Blunk, T., Muller, R. H., Kresse, M. The influence of the sample preparation on plasma protein adsorption patterns on polysaccharidestabilized iron oxide particles and N-terminal micro sequencing of unknown proteins. J Drug Target; 5, p. 35-43 (1997).

Vandenberghe, R. E., Barrero, C. A., Costa, G. M., VanSan, E. De Grave E. Mössbauer 
characterization of iron oxides and (oxy)hydroxides: the present state of the art Hyperfine Interactions 126 , p. 247-259 (2000).

Vijayakumar, R., Koltypin, Y., Felner, I., Gedanken, A. Sonochemical synthesis and characterization of pure nanometer-sized $\mathrm{Fe}_{3} \mathrm{O}_{4}$ particles. Mater.
Sci. Eng. 286 p. 101 (2000).

Weissleder, R., Elizondo, G., Wittenberg, J., Rabito, C. A., Bengele, H. H., Josephson, L. Ultrasmall superparamagnetic iron oxide: characterization of a new class of contrast agents for MR imaging. Radiology; 175, p. 489-93 (1990). 